\title{
Computation of mode I Strain Energy Release Rate of symmetrical and asymmetrical sandwich structures using mixed finite element
}

\author{
Mohamed Ben Ali Amina \\ Civil Engineering department, University of August 20, 1955, Skikda, Algeria. \\ benaliamina21@gmail.com \\ Bouziane Salah, Bouzerd Hamoudi \\ Civil Engineering department, University of August 20, 1955, Skikda, Algeria. \\ Laboratory of Civil Engineering and Hydraulics, University of May 8, 1945, Guelma, Algeria. \\ bouriane_21@yahoo.fr, bttp:/ /orcid.org/0000-0002-0831-1167 \\ bib_ham@yahoo.fr, bttp://orcid.org/0000-0002-8216-2980
}

\begin{abstract}
The use of composite materials is on the rise in different engineering fields. The main advantage of these materials for the aerospace industry being their low weight for excellent mechanical qualities. The analysis of failure modes, such as delamination, of these materials has received great attention from researchers. This paper proposes a method to evaluate the mode I Strain Energy Release Rate (SERR) of sandwich structures. This method associates a two-dimensional mixed finite element with virtual crack extension technique for the analysis of interfacial delamination of sandwich beams. The cases of a symmetrical Double Cantilever Beam (DCB) and a asymmetrical Double Cantilever Beam (UDCB) have been analyzed in this study. The comparison of the results obtained by this method with those found in the literature shows efficiency and good precision for the calculation of Strain Energy Release Rate (SERR).
\end{abstract}

KEYWORDS. Numerical modelling; Cracking; Mixed finite element; Sandwich structures; Strain energy release rate.

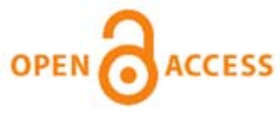

Citation: Mohamed Ben Ali, A., Bouziane, S., Bouzerd, H., Computation of mode I strain energy release rate of symmetric and asymmetrical sandwich structures using mixed finite element, Frattura ed Integrità Strutturale, 56 (2021) 229-239.

Received: 16.02 .2021

Accepted: 22.03 .2021

Published: 01.04.2021

Copyright: (C) 2021 This is an open access article under the terms of the CC-BY 4.0, which permits unrestricted use, distribution, and reproduction in any medium, provided the original author and source are credited.

\section{INTRODUCTION}

$\mathrm{S}$ andwich structures offers a lot of advantages in many applications ranging from satellites, aircraft, ships, automobiles, rail cars, wind energy systems, and bridge construction to mention only a few. Due to the need of developing new materials with high performance and low-weight their use continues to increase rapidly. Sandwich structures have two stiff, strong skins separated by a low stiffness core. Their concepts have an excellent construction technique which combines weight with rigidity and strength. 
However, overall bearing capacity of the sandwich component is often limited not by the strength of the face sheets, but by the strength of the core material and the bond between the two components [1]. Therefore, strength and stiffness are usually considered as being fundamentally important criteria in the selection of a core material for sandwich application[2].

Among the most important phenomena in the study of composite materials in general and sandwich structures in particular is cracking which can lead to a local or global collapse of the structure. Cracks generated by low-speed impacts which are often accidental in nature, can propagate to a premature failure of the structure [3]. Furthermore, the most common type of failure in the composite structures is relevant to delamination and debonding of composite assemblies, that's why many previous studies have focused on the study of failure in sandwich beams. Other studies, however, have been devoted to understanding and characterizing cracks properties and the interface fracture using different analytical, numerical and experimental methods.

Avilés and Carlsson [4] analyzed the compliance and the energy release rate of the sandwich double cantilever beam (DCB) specimen using the beam theory, elastic foundation analysis (EFA) and finite element analysis (FEA). Østergaard et al [5] presented an analytical evaluation of the J-integral for the purpose of calculating the energy release rate for interface cracking of a sandwich specimen with isotropic face sheets. Nairn [6] calculated the energy release rate in heterogeneous laminates using residual stresses. Wang and Zhang [7] developed a new analytical solution for the calculation of the energy release rate where they have analyzed the typical delaminated sandwich and adhesively bonded joint specimens. They analyzed the stress field using an interface stress-based method. Davidson et al [8] obtained experimentally the critical mode I and mode II energy release rates in a sandwich composite panel using Double Cantilever Beam by modifying the geometry of the sandwich structure, to obtain (UDCB), and End Notch Flexure (ENF) tests, respectively. Shah and Tarfaoui [9] compared the different approaches to calculate the strain energy release rates of mode I \& II in composite foam core sandwiches of the wind turbine industry. An experimental study used a single density of foam core for the most part of the turbine blade to determine the effect of scale on the calculation of SERR with different thicknesses of the foam cores. Shah and Tarfaoui [10] studied the effect of adhesive thickness on the mode I and II strain energy release rates, comparative study was carried out using different approaches for the calculation of mode I and II SERR.

The main objective of this study is to propose a method for the calculation of the mode I Strain Energy Release Rate (SERR) and to validate its results on cases, which were well established by some researches. This method combines a twodimensional mixed finite element with the virtual crack extension technique to calculate the strain energy release rate of crack interfaces in sandwich beams. A Double Cantilever Beam (DCB) [11-13] and asymmetrical Double Cantilever Beam (UDCB) [14-16] tests have been studied in this paper.

Several numerical tests, for different values of the initial crack size and sandwich beam dimensions, were analyzed and the results obtained using the proposed method were compared with those found in the literature.

\section{MIXED FINITE ELEMENT}

7 he sandwich structure have been discretized using a special mixed finite element RMQ-7 (Reissner Modified Quadrilateral) as shown in Fig. 1. The element is a quadrilateral mixed finite element with 7 nodes and 14 degrees of freedom[17]. The final configuration of the element, in a natural $(\xi, \eta)$ plane, was obtained after the three following stages[18]: (i) construction of the parent element by adding a displacement node (node 5); (ii) delocalization of some variables inside the element and displacement of static nodal unknown of the corners towards the side itself; (iii) static condensation of the internal unknown variables to obtain the final form of the present mixed finite element.

The obtained element has three of its sides compatible with linear traditional elements and presents a displacement node at each corner. On the fourth side, in addition to its two displacement nodes of corner (node 1 and node 2), There are three additional nodes: a median node (node 5) and two intermediate nodes in the medium on each half-side (nodes 6 and 7), introducing the components of the stress vector along the interface. The formulation and the validation of the element have been presented by Bouziane et al. [18].

The element displacement component is approximated by:

$$
\{u\}=[N]\{q\}
$$

where $\{\mathrm{q}\}^{\mathrm{t}}=\left\{\mathrm{u}_{1}^{1}, \mathrm{u}_{2}^{1}, \mathrm{u}_{1}^{2}, \mathrm{u}_{2}^{2}, \mathrm{u}_{1}^{3}, \mathrm{u}_{2}^{3}, \mathrm{u}_{1}^{4}, \mathrm{u}_{2}^{4}, \mathrm{u}_{1}^{5}, \mathrm{u}_{2}^{5}\right\}$ is the vector of nodal displacements and [N] is the matrix of interpolation functions for displacements.

The shape functions are: 


$$
\begin{array}{ll}
N_{1}=\frac{1}{2}(1-\xi)(1-\eta) \xi \quad, \quad N_{2}=\frac{1}{4}(1+\xi)(1-\eta) \xi \quad, \quad N_{3}=\frac{1}{4}(1+\xi)(1+\eta) \\
N_{4}=\frac{1}{4}(1-\xi)(1+\eta) \quad, \quad N_{5}=\frac{1}{2}\left(1-\xi^{2}\right)(1-\eta)
\end{array}
$$

The stress field in any point is written as:

$$
\{\sigma\}=[M]\{\tau\}
$$

where $[\mathrm{M}]$ is the matrix of interpolation functions for stresses and $\{\tau\}$ is the vector of nodal stresses.

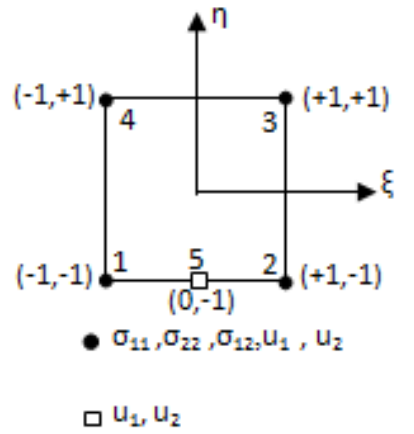

Parent element

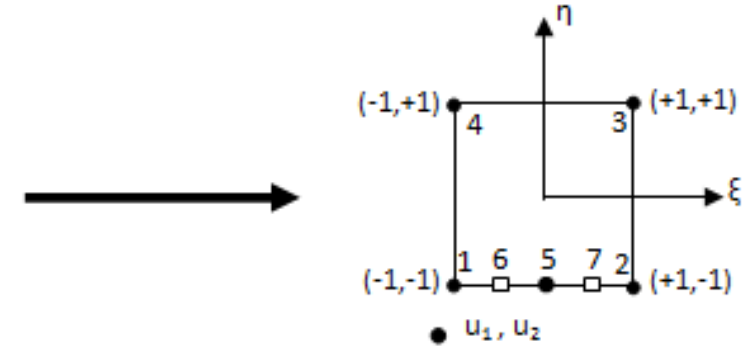

$\sigma^{\sigma_{22}, \sigma_{12}}$

RMQ-7 element

Figure 1: Mixed finite element RMQ-7.

In the configuration of Fig. 1 , the shape functions used to approximate $\sigma_{11}$ are given by:

$$
\begin{array}{rlrl}
\mathrm{M}_{11}^{8} & =\frac{1}{4}(1+2 \xi)(1+2 \eta) & , & \mathrm{M}_{11}^{9}=\frac{1}{4}(1-2 \xi)(1+2 \eta) \\
\mathrm{M}_{11}^{10}=\frac{1}{4}(1-2 \xi)(1-2 \eta) & , & \mathrm{M}_{11}^{11}=\frac{1}{4}(1+2 \xi)(1-2 \eta)
\end{array}
$$

The shape functions used to calculate $\sigma_{12}$ and $\sigma_{22}$ are given as follows:

$$
\begin{array}{ll}
\mathrm{M}_{\mathrm{i} 2}^{6}=\frac{1}{6}(1-2 \xi)(1-2 \eta) \quad, \quad & \mathrm{M}_{\mathrm{i} 2}^{7}=\frac{1}{6}(1+2 \xi)(1-2 \eta) \\
\mathrm{M}_{\mathrm{i} 2}^{8}=\frac{1}{3}(1+2 \xi)(1+\eta) \quad, \quad \mathrm{M}_{\mathrm{i} 2}^{9}=\frac{1}{4}(1-2 \xi)(1+\eta) \quad, \quad \mathrm{i}=1,2
\end{array}
$$

It should be noted that nodes 8, 9, 10 and 11 are inside the element, and which are eliminated by the static condensation technique [18].

The nodal approximation of the displacement and stress fields is expressed by:

$$
\left\{\begin{array}{l}
\{\sigma\} \\
\{\varepsilon\}
\end{array}\right\}=\left[\begin{array}{cc}
{[\mathrm{M}]} & {[0]} \\
{[0]} & {[\mathrm{B}]}
\end{array}\right]\left\{\begin{array}{l}
\{\tau\} \\
\{\mathrm{g}\}
\end{array}\right\}
$$


where $[\mathrm{B}]$ is the strain-displacement transformation matrix.

The element matrix $\left[\mathrm{K}_{\mathrm{e}}\right]$ is given by:

$$
\left[K_{e}\right]=\left[\begin{array}{cc}
{\left[K_{\sigma \sigma}\right]} & {\left[K_{\sigma u}\right]} \\
{\left[K_{\sigma u}\right]^{t}} & {[0]}
\end{array}\right]
$$

Here the sub-matrix $\left[\mathrm{K}_{\sigma \sigma}\right]$ is defined by:

$$
\left[K_{\sigma \sigma}\right]=-t \int_{A_{e}}[M]^{T}[S][M] d A^{e}
$$

and the sub-matrix $\left[\mathrm{K}_{\sigma u}\right]$ is given by:

$$
\left[K_{\sigma u}\right]=t \int_{A_{e}}[M]^{T}[B] d A^{e}
$$

where: $\mathrm{t}$ is the thickness, $[\mathrm{S}]$ is the compliance matrix, $\mathrm{A}^{\mathrm{e}}$ is the element area and $\mathrm{T}$ indicate the matrix transpose.

\section{COMPUTATION OF STRAIN ENERGY RELEASE RATE}

7 he virtual crack extension method associated with the mixed finite element RMQ-7 is used to calculate the strain energy release rate $G[17]$. In this technique, the first calculation of the deformation energy $\Pi_{1}$ is carried out in the initial configuration of the crack. The crack is then moved by an infinitesimal distance $\delta a$ in the direction of its axis (Fig. 2) and the deformation energy $\Pi_{2}$ is calculated. The energy release rate $G$ will be evaluated thereafter starting from the following relation:

$$
G=-\frac{\Pi_{2}-\Pi_{1}}{\delta a}=-\frac{\delta \Pi}{\delta a}
$$

Indeed the intermediate displacement node of the RMQ-7 element is associated to crack tip, and consequently the length of crack "a" can be increased by a quantity $\delta$ a while acting inside strict of the crack element by translation of the tip crack node without disturbing the remainder of the mesh.

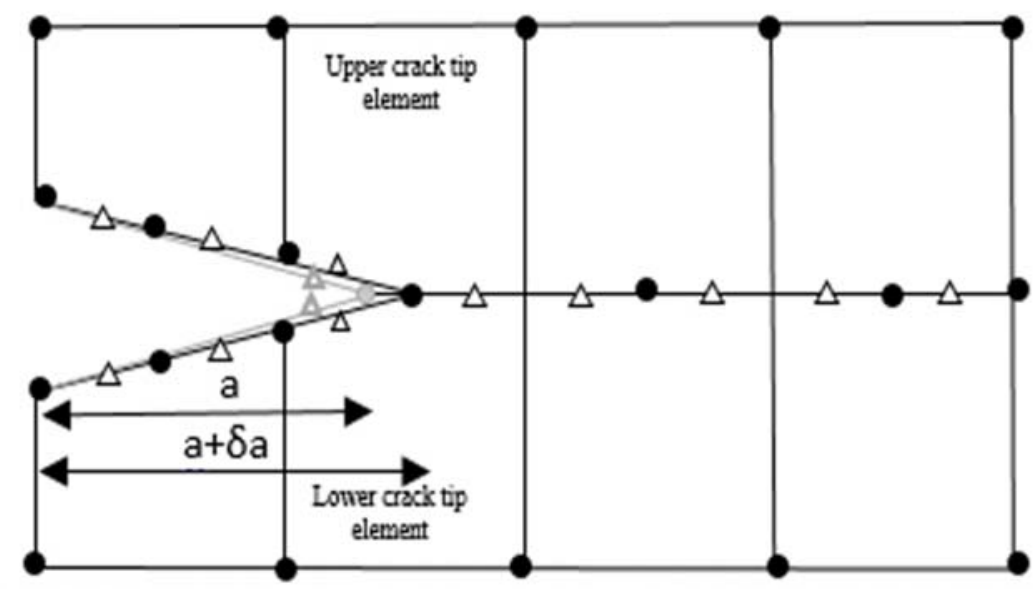

Figure 2: Mesh around tip crack after extension $\delta a$. 
If we consider that the external loading does not vary during the increase in $\delta a$, the energy release rate is calculated as follows:

$$
G=-\frac{\Pi(a+\delta a)-\Pi(a)}{\delta a}
$$

where $\Pi(\mathrm{a}+\delta \mathrm{a})$ and $\Pi(\mathrm{a})$ represent respectively the deformation energy of the cracked structure in the configuration $a+\delta a$ and "a".

With the assumption of linear elastic behavior and small displacements, the solutions $u(a)$ and $u(a+\delta a)$ are as close as the disturbance $\delta \mathrm{a}$ is small compared to the dimensions of the crack element. The energy release rate $\mathrm{G}$ becomes:

$$
G=-\frac{1}{2 \delta a} \sum_{i=1}^{n e}\{u(a+\delta a)\}_{i}^{T}\left[[K(a+\delta a)]_{i}-[K(a)]_{i}\right]\{u(a+\delta a)\}_{i}
$$

with:

ne : total number of elements in discretized structure,

$\{\mathrm{u}\}_{\mathrm{i}}$ : vertical vector containing the nodal values of element $\mathrm{i}$,

$[\mathrm{K}]_{\mathrm{i}}$ : elementary matrix of element $\mathrm{i}$, and the exponent " $\mathrm{T}$ " indicates the transposed vector.

As only the crack element is disturbed, then $G$ results more simply in the relation:

$$
G=-\frac{1}{2 \delta a}\{u(a+\delta a)\}_{c}^{T}\left[[K(a+\delta a)]_{c}-[K(a)]_{c}\right]\{u(a+\delta a)\}_{c}
$$

where the index "c" indicates that the matrix and vector used are those of the crack element.

The expression of $\mathrm{G}$ can be written differently as follows:

$$
G=-\frac{1}{2}\{u\}_{c}^{T} \frac{[\delta K]_{f}}{\delta a}\{u\}_{c}
$$

After the resolution phase, the nodal values of the crack element are extracted, and a special module is used to evaluate the energy release rate according to the following formula:

$$
G=-\frac{1}{2}\{u\}_{c}^{T} \frac{[\Delta K]_{f}}{\Delta a}\{u\}_{c}
$$

\section{RESULTS AND DISCUSSIONS}

$\mathrm{T}$

he present mixed finite element, associated with the virtual crack extension method, was used to carry out numerical tests on sandwich beams. For the examples treated in this study, the geometric and mechanical characteristics of the samples tested are the same found in the literature in order to compare the results found under the same conditions.

\section{Symmetrical Double Cantilever Beam (DCB) test}

The specimens used to model the pure mode I strain energy release rates of the symmetrical sandwich structure are of the type Double Cantilever Beam(DCB), the core-skin interfaces of which are shown schematically in the Fig. 3. The sandwich specimens are made up of a $45^{\circ}$ Biax type composite face plate joined to a PVC foam core of $80 \mathrm{~kg} / \mathrm{m} 3$ density with different thicknesses 10, 20 and $30 \mathrm{~mm}$. The face plates for all of the specimens are $2 \mathrm{~mm}$ thick [9]. 


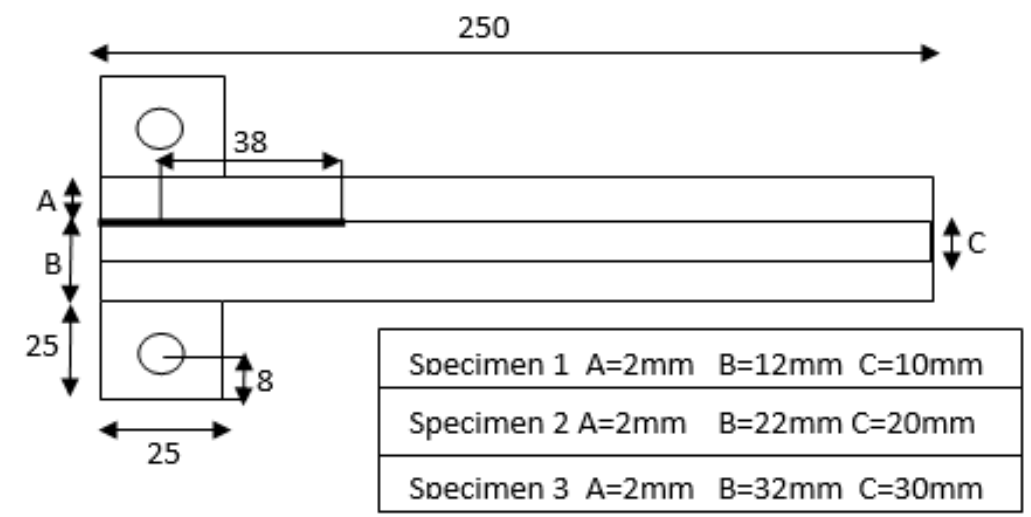

Figure 3: Double Cantilever Beam (DCB) test coupon geometry [9].

The mechanical properties of the composite material in the fiber direction are given in Tab. 1.

\begin{tabular}{cccc}
\hline Fiber direction & Modulus $\mathrm{E}(\mathrm{GPa})$ & Poisson's ratio $v_{\text {avg }}$ & Resistance (MPa) \\
$0^{0}$ & $\mathrm{E}_{\mathrm{L}} 48.11 \pm 6$ & $v_{\mathrm{LT}} 0.28 \pm 0.3$ & $\mathrm{X}(\mathrm{MPa}) 965.50 \pm 25$ \\
$90^{\circ}$ & $\mathrm{E}_{\mathrm{T}} 11.21 \pm 2$ & $v_{\mathrm{TL}} 0.096 \pm 0.010$ & $\mathrm{Y}(\mathrm{MPa}) 33.50 \pm 3$ \\
$45^{0}$ & $\mathrm{G}_{\mathrm{LT}} 4.42 \pm 0.5$ & & $\mathrm{Savg}(\mathrm{MPa}) 48.69 \pm 3$ \\
\hline
\end{tabular}

Table 1: Mechanical properties of the composite material in the fiber direction [9].

The different specimens of symmetrical Double Cantilever Beam were modeled using the proposed mixed finite element in order to calculate the mode I strain energy release rate at initiation $\mathrm{G}_{\mathrm{Ii}}$ by the method proposed in this study. Different meshes were used to test the convergence and the precision of the results.

The calculation of the mode I Strain Energy Release Rate (SERR) is made by conducting Double Cantilever Beam (DCB) test using the mixed finite element RMQ7. Then, it was compared with that of Shah and Tarfaoui [9], who used modified beam theory 1 and 2 (MBT1, MBT2), compliance calibration method (CC) and virtual crack closure technique (VCCT) (see Tab. 2). These analytical approaches are based on the classical beam theory and are formulated for the evaluation of $G$ in mode I. They are listed in the following:

\section{Modified Beam Theory 1 (MBT 1)}

The modified beam theory models the DCB specimen as a simple cantilever beam based on the Timoshenko beam theory [9]:

$$
\mathrm{G}_{\mathrm{I}}=\frac{3 \mathrm{P} \delta}{2 b a}
$$

with $\mathrm{P}$ is the load to give a $\delta$ displacement, $\mathfrak{a}$ is the crack length and $\mathrm{b}$ is the specimen width.

\section{Modified Beam Theory 2 (MBT 2)}

In the modified beam theory 2 , the rotation of the crack front as well as the partially cracked interface are considered to account for the fiber bridging [9]:

$$
\mathrm{G}_{\mathrm{I}}=\frac{3 \mathrm{P} \delta}{2 b(a+|\Delta|)}
$$

with $\mathrm{P}$ is the applied load, $\delta$ is the displacement of the two beams, $\mathfrak{a}$ is the crack length, $\mathrm{b}$ is the specimen width and $\Delta$ is the crack front rotation correction factor. 


\section{Compliance Calibration Method (Cc)}

With the compliance calibration method, the compliance was considered as a function of the crack length [9]. The formulation for $\mathrm{G}_{\mathrm{I}}$ is thus given by:

$$
\mathrm{G}_{\mathrm{I}}=\frac{\mathrm{nP}^{2} \mathrm{R} a^{h-1}}{2 b}
$$

where $\mathrm{R}$ is anti-natural $\log$ of the intersection of a plot between $\mathrm{L} \eta(\mathrm{c})$ and $\mathrm{L} \eta(\mathrm{a})$.

\section{Virtual crack closure technique (VCCT)}

The formulation of $\mathrm{G}_{\mathrm{I}}$ given by [9] is:

$$
\mathrm{G}_{\mathrm{I}}=\frac{\sigma_{\mathrm{M} 3}\left(\mathrm{w}_{\mathrm{U}}-\mathrm{w}_{\mathrm{L}}\right)}{2}
$$

\begin{tabular}{|c|c|c|}
\hline \multicolumn{3}{|c|}{ Specimen 1. Sandwich Beam: Skin 2mm, Core 10mm } \\
\hline & Method & $\mathrm{G}_{\mathrm{Ii}}\left(\mathrm{kJ} / \mathrm{m}^{2}\right)$ \\
\hline $\begin{array}{c}\text { Present mixed finite } \\
\text { element }\end{array}$ & RMQ-7 & 0.465 \\
\hline \multirow{4}{*}{ Shah and Tarfaoui [9] } & MBT1 & 0.452 \\
\hline & MBT2 & 0.520 \\
\hline & $\mathrm{CC}$ & 0.563 \\
\hline & VCCT & 0.488 \\
\hline \multicolumn{3}{|c|}{ Specimen 2. Sandwich Beam: Skin $2 \mathrm{~mm}$. Core $20 \mathrm{~mm}$} \\
\hline & Method & $\mathrm{G}_{\mathrm{Ii}}\left(\mathrm{kJ} / \mathrm{m}^{2}\right)$ \\
\hline $\begin{array}{c}\text { Present mixed finite } \\
\text { element }\end{array}$ & RMQ-7 & 0.459 \\
\hline \multirow{4}{*}{ Shah and Tarfaoui [9] } & MBT1 & 0.436 \\
\hline & MBT2 & 0.446 \\
\hline & $\mathrm{CC}$ & 0.405 \\
\hline & VCCT & 0.593 \\
\hline \multicolumn{3}{|c|}{ Specimen 3. Sandwich Beam: Skin 2mm. Core 30mm } \\
\hline & Method & $\mathrm{G}_{\mathrm{Ii}}\left(\mathrm{kJ} / \mathrm{m}^{2}\right)$ \\
\hline $\begin{array}{c}\text { Present mixed finite } \\
\text { element }\end{array}$ & RMQ-7 & 0.579 \\
\hline \multirow{4}{*}{ Shah and Tarfaoui [9] } & MBT1 & 0.533 \\
\hline & MBT2 & 0.571 \\
\hline & $\mathrm{CC}$ & 0.813 \\
\hline & VCCT & 0.662 \\
\hline
\end{tabular}

The nodes "U" and " $\mathrm{L}$ " are displaced through " $\mathrm{W}_{\mathrm{U}}$ " and " $\mathrm{W}_{\mathrm{L}}$ " in the vertical direction

Table 2: Energy release rates obtained from DCB tests. 
Tab. 2 shows the comparison of the results obtained for different values of the core thickness. The results found using the proposed method are in good agreement with the values obtained by different analytical approaches [9]. The results show that with a monotonic increase in the core thickness from 10 to $30 \mathrm{~mm}$, the value of $\mathrm{G}_{\mathrm{I}}$ grows non-monotonically. This effect has been observed experimentally [9] and it is mainly due to the resin penetration in the core-face interface, which modifies the stiffness of the core material and hence the behavior of the interface. Numerically, due to the choice of the value of virtual extension of crack on the level of the interface, which will influence the rigidity of the elements at the interface face-core. Consequently, it influences the value of the Strain Energy Release Rate (SERR).

\section{Asymmetrical Double Cantilever Beam (UDCB) test}

The specimens used to model the pure mode I strain energy release rates is that the asymmetrical Double Cantilever Beam (UDCB), in order to produce a dominant mode I loading. Due to their large utilization a double cantilever beam specimens are typically used in this study with some modification which was developed by Davidson et al.[8]. The asymmetrical UDCB specimen (Fig. 4) was used with simple modification of the geometry such that the intended plane of fracture coincides with the neutral axis [8].

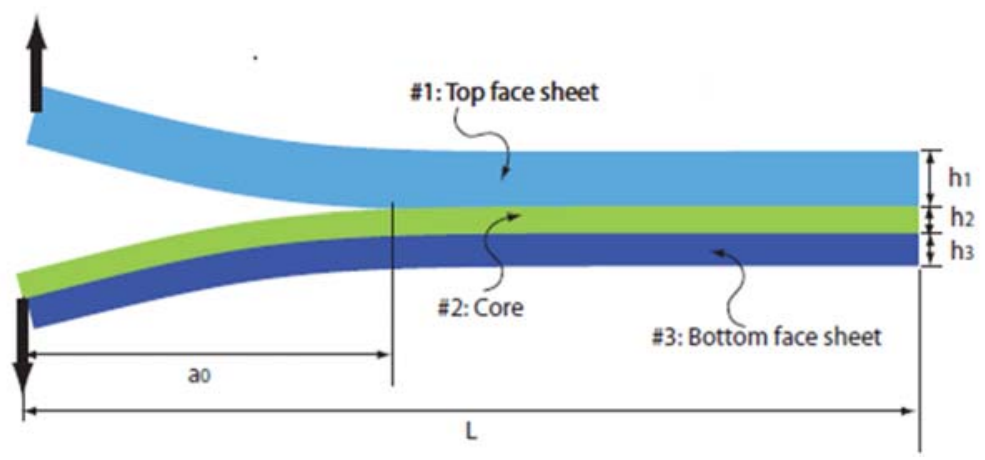

Figure 4:UDCB specimen used for Mode I fracture resistance test [8].

Fig. 4 shows the geometry of the sample of the UDCB specimen and specify interface and crack location, where the interfaces in question are between the foam core and face sheet of the sandwich panel and the crack between the top face sheet and the core. The dimensions of the sandwich beam are given in Tab. 3 .

\begin{tabular}{cccccc}
\hline $\mathrm{L}(\mathrm{mm})$ & $\mathrm{b}(\mathrm{mm})$ & $\mathrm{h}_{1}(\mathrm{~mm})$ & $\mathrm{h}_{2}(\mathrm{~mm})$ & $\mathrm{h}_{3}(\mathrm{~mm})$ & $\mathrm{a}_{0}(\mathrm{~mm})$ \\
120 & 25.4 & 4.83 & 3.5 & 2.76 & 53 \\
\hline
\end{tabular}

Table 3: Dimensions of asymmetrical DCB [8].

The material properties of the bi-axial face sheet and core are given in Tab. 4.

\begin{tabular}{cccc}
\hline & Modulus $\mathrm{E}(\mathrm{GPa})$ & Poisson's ratio $v_{\text {avg }}$ & $\begin{array}{c}\text { Modulus of rigidity } \\
\mathrm{G}(\mathrm{GPa})\end{array}$ \\
Composite & $\mathrm{E}_{11} 11.5$ & $\boldsymbol{v}_{12} 0.3$ & $\mathrm{G}_{12} 3.0$ \\
Core & $\mathrm{E}_{22} 8.0$ & $v_{21} 0.25$ & \\
& $\mathrm{E}_{11} 3.0$ & $\boldsymbol{v}_{12} 0.3$ & $\mathrm{G}_{12} 1.2$ \\
\hline
\end{tabular}

Table 4: Nominal specimen material properties[8].

Numerical simulations of the asymmetrical DCB test were made using the mixed finite element RMQ-7 for the calculation of mode I strain energy release rate. Several meshes were used in these simulations to ensure the convergence of the results. Tab. 5 shows the comparison between the mixed finite element prediction and experimental value [8]. 


\begin{tabular}{cc}
\hline & $\mathrm{G}_{\mathrm{I}}\left(\mathrm{kJ} / \mathrm{m}^{2}\right)$ \\
Present mixed finite element & 2.29 \\
Davidson et al [8] & 2.08 \\
\hline
\end{tabular}

Table 5: Comparison of calculated and experimental data for UDCB tests.

The difference between the value of the mode I strain energy release rate, given by the present mixed finite element, and these empirical findings [8] is 10\%. This difference is very acceptable because in calculations, the layers are considered as a direct assembly, but in reality, the adhesive between them has certain mechanical properties. For this reason, the findings show that the value of the mode I strain energy release rate, given by the proposed method, and that of found experimentally, are in a good agreement [8].

Several specimens with different dimensions of the sandwich beam layers were used in these numerical simulations. The variation of the dimensions was made in the same way for the different layers. Tab. 6 gives the results obtained of the mode I strain energy release rate for the different cases.

\begin{tabular}{|c|c|}
\hline & $\mathrm{G}_{\mathrm{I}}\left(\mathrm{kJ} / \mathrm{m}^{2}\right)$ \\
\hline $\begin{array}{l}\text { Asymmetrical Sandwich Beam specimen 1: } \\
\mathrm{h}_{1}=4.83 \mathrm{~mm} \mathrm{~h} \mathrm{~h}_{2}=3.5 \mathrm{~mm} \mathrm{~h} \mathrm{~h}_{3}=2.76 \mathrm{~mm}\end{array}$ & 2.29 \\
\hline $\begin{array}{l}\text { Asymmetrical Sandwich Beam specimen 2: } \\
\mathrm{h}_{1}=6.83 \mathrm{~mm} \quad \mathrm{~h}_{2}=5.5 \mathrm{~mm} \quad \mathrm{~h}_{3}=4.76 \mathrm{~mm}\end{array}$ & 2.20 \\
\hline $\begin{array}{l}\text { Asymmetrical Sandwich Beam specimen 3: } \\
\mathrm{h}_{1}=8.83 \mathrm{~mm} \quad \mathrm{~h}_{2}=7.5 \mathrm{~mm} \quad \mathrm{~h}_{3}=6.76 \mathrm{~mm}\end{array}$ & 2.62 \\
\hline
\end{tabular}

Table 6: Strain Energy Release Rate for UDCB of different sizes.

Noting a certain stability of the values obtained by keeping the same ratio between the dimensions of the different layers of the sandwich beam.

The computation of mode I Strain Energy Release Rate (SERR) of symmetrical and asymmetrical sandwich beams cracks is given in this paper. The results obtained using the present mixed finite element RMQ-7 was compared with analytical and experimental results, for that the following conclusions can be made:

- the results of both symmetrical Double Cantilever Beam (DCB) and asymmetrical Double Cantilever Beam (UDCB) tests show a very slight difference between the numerical simulation and the previous studies. This difference is very reasonable taking into account the possible defects during the process of the development of the sandwich beam.

- we should note that the adhesive between the skins and the core in the numerical study is considered as a direct assembly but in the experimental study it is a resin with significant mechanical characteristics.

\section{Delamination of Double Cantilever Beam (DCB)}

For the determination of the critical strain energy release rate of mode I, another example which treats the problem of delamination of a symmetrical DCB was studied. This experimental study was carried out by Djemai [19] for which we have all the data necessary to calculate the critical strain energy release rate (Fig. 5).

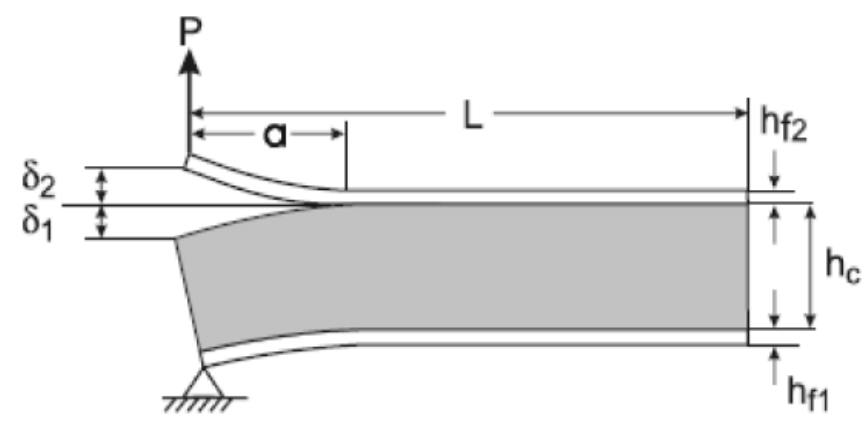

Figure 5: Delamination of Double Cantilever Beam [19]. 
The Tab. 7 shows the geometrical dimensions of the DCB specimen used.

\begin{tabular}{cccc}
\hline $\begin{array}{c}\text { Length } \\
(\mathrm{mm})\end{array}$ & $\begin{array}{c}\text { Width } \\
(\mathrm{mm})\end{array}$ & $\begin{array}{c}\text { Skin thickness } \\
(\mathrm{mm})\end{array}$ & $\begin{array}{c}\text { Core thickness } \\
(\mathrm{mm})\end{array}$ \\
180 & 20 & 3.5 & 15 \\
\hline \multicolumn{4}{c}{ Table 7: Dimensions of DCB. }
\end{tabular}

The sandwich is made up with Glass-Polyester as skin and Cork agglomerate as core [19]. The mechanical properties of the composite material are given in Tab. 8.

\begin{tabular}{cccc}
\hline & Modulus $\mathrm{E}(\mathrm{GPa})$ & Poisson's ratio $v_{\text {avg }}$ & $\begin{array}{c}\text { Modulus of rigidity } \\
\mathrm{G}(\mathrm{GPa})\end{array}$ \\
Composite & $\mathrm{E}_{11} 4.995$ & $v_{12} 0.3675$ & $\mathrm{G}_{12} 1.827$ \\
& $\mathrm{E}_{22} 4.997$ & $v_{21} 0.3675$ & \\
Core & $\mathrm{E}_{11} 21$ & $v_{12} 0.05$ & $\mathrm{G}_{12} 4.3$ \\
\hline
\end{tabular}

Table 8: Nominal specimen material properties [19].

Tab. 9 shows the comparison between the experimental values obtained by Djemai [19] and those found by the proposed mixed finite element for various values of the critical load "P" and the size of crack "a".

\begin{tabular}{cccc}
\hline & & $\begin{array}{c}\text { Djemai [19] } \\
\mathrm{a}(\mathrm{mm})\end{array}$ & $\begin{array}{c}\text { Present mixed finite } \\
\text { element } \\
\mathrm{G}_{\mathrm{IC}}\left(\mathrm{kJ} / \mathrm{m}^{2}\right)\end{array}$ \\
30 & $\mathrm{P}(\mathrm{N})$ & 0.0634 & 0.0638 \\
40 & 23.03 & 0.0565 & 0.0542 \\
50 & 18.32 & 0.0648 & 0.0639 \\
60 & 14.53 & 0.0678 & 0.0657 \\
70 & 13.12 & 0.0650 & 0.0647 \\
& 12.64 & $\mathbf{0 . 0 6 3 5}$ & $\mathbf{0 . 0 6 2 4}$ \\
& $\mathbf{G}_{\mathrm{IC}}$ & $\mathbf{0 . 0 0 3 7 9}$ & $\mathbf{0 . 0 0 4 4 5}$ \\
\hline
\end{tabular}

Table 9: Comparison of the strain energy release rate for mode I.

The results obtained of the mode I strain energy release rate using the proposed method are in good agreement with experimental values given by Djemai [19].

According to the results obtained, one notices that each time the length of the crack increases, the critical load decreases, the energy release rate remains almost constant with the variation of the size of the crack, which indicates that the resistance to the starting of delamination remains constant in spite of the variation of the initial size of the crack between the skin and the core in the sandwich.

\section{CONCLUSION}

I $\mathrm{n}$ this paper, a method for the calculation of the mode I strain energy release rate for cracked sandwich structures has been proposed. This method associated a two-dimensional mixed finite element with virtual crack extension technique for the analysis of interfacial delamination of sandwich beams. Symmetrical Double Cantilever Beam (DCB) and asymmetrical Double Cantilever Beam (UDCB) cases have been analyzed in this study.

The use of the present mixed finite element makes it possible to introduce one mesh for the calculation of the strain energy release rate, which represents a considerable profit in computing times and setting in data compared to the traditional techniques which use two meshes.

The results obtained using the proposed model were compared with those found experimentally or obtained by other techniques proposed in the literature. The analysis of the results shows the efficiency and the good performance of the 
proposed method for the evaluation of the strain energy release rate for symmetrical and asymmetrical cracked sandwich beams.

The difference between the values of the mode I strain energy release rate, given by the present mixed finite element, and that of found experimentally is attributed to the fact that in calculations, the layers are considered as a direct assembly, but in fact, the adhesive between them has some mechanical properties. In this case, neglecting this fact gives rise to an underestimation or an overestimation of the strain energy release rate values.

\section{REFERENCES}

[1] El-Sayed,S., Sridharan, S. (2002). Cohesive layer models for predicting delamination growth and crack kinking in sandwich structures, International Journal of Fracture.,117, pp. 63-84.

[2] Vinson, J.R. (2005). Sandwich Structures: Past, Present, and Future, Sandw. Struct. 7 Adv. with Sandw. Struct. Mater., Aalborg University, Aalborg, Denmark, pp. 3-12, DOI: 10.1007/1-4020-3848-8_1.

[3] Peng, L. (2013). Modélisation numérique d'assemblages collés: application à la réparation de structures en composites , Thèse de doctorat. Université de Bourgogne.

[4] Aviliés, F., Carlsson, L.A. (2008). Analysis of the sandwich DCB specimen for debond characterization, Engineering Fracture Mechanics., 75, pp. 153-68, DOI: 10.1016/j.engfracmech.2007.03.045.

[5] Østergaard, R.C., Sørensen, B.F. (2007). Interface crack in sandwich specimen,Int J Fract., 143, pp. 301-316, DOI: $10.1007 /$ s10704-007-9059-4.

[6] Nairn, J.A. (2006). On the calculation of energy release rates for cracked laminates with residual stresses, Int. J. Fract., 139(2), pp. 267-93, DOI: 10.1007/s10704-006-0044-0.

[7] Wang, J., Zhang, C. (2009). Energy release rate and phase angle of delamination in sandwich beams and symmetric adhesively bonded joints, Int. J. Solids Struct.,46, pp. 4409-4418, DOI: 10.1016/j.ijsolstr.2009.09.003.

[8] Davidson, P., Waas, A.M., Yerramalli, C.S. (2012). Experimental determination of validated , critical interfacial modes I and II energy release rates in a composite sandwich panel, Compos. Struct., 94(2), pp. 477-483, DOI: $10.1016 /$ j.compstruct.2011.08.007.

[9] Shah, O.R., Tarfaoui, M. (2017). Determination of mode I \& II strain energy release rates in composite foam core sandwiches. An experimental study of the composite foam core interfacial fracture resistance, Compos. Part B Eng., 111, pp. 134-142, DOI: 10.1016/j.compositesb.2016.11.044.

[10] Shah, O.R., Tarfaoui, M. (2016). Effect of adhesive thickness on the Mode I and II strain energy release rates. Comparative study between different approaches for the calculation of Mode I\& II SERR's, Compos. Part B Eng., 96, pp. 354-363, DOI: 10.1016/j.compositesb.2016.04.042.

[11] Ma, M., Yao, W., Chen, Y. (2018). Critical energy release rate for facesheet/core delamination of sandwich panels, Eng. Fract. Mech., 204(September), pp. 361-368, DOI: 10.1016/j.engfracmech.2018.10.029.

[12] Balaban, A.C., Tee, K.F. (2019). Strain energy release rate of sandwich composite beams for different densities and geometry parameters, Theor. Appl. Fract. Mech., 101(February), pp. 191-199, DOI: 10.1016/j.tafmec.2019.03.001.

[13] Moroni, F., Pirondi, A. (2019). Comparison of tensile strength and fracture toughness under mode I and II loading of co-cured and co-bonded CFRP joints, 47, pp. 294-302, DOI: 10.3221/IGF-ESIS.47.22.

[14] Sundararaman, V., Davidson, B.D. (1997). An unsymmetric double cantilever beam test for interfacial fracture toughness determination, Int J Solids Struct.,34(7), pp. 799-817.

[15] Ma, M., Yao, W., Li, P. (2020). Critical energy release rate for interface delamination of asymmetrical specimen, Compos. Struct., 237(September 2019), pp. 111919, DOI: 10.1016/j.compstruct.2020.111919.

[16] Zambelis, G., Da Silva Botelho, T., Klinkova, O., Tawfiq, I., Lanouette, C. (2018). Evaluation of the energy release rate in mode I of asymmetrical bonded composite/metal assembly, Eng. Fract. Mech., 190, pp. 175-185, DOI: $10.1016 /$ j.engfracmech.2017.12.007.

[17] Bouzerd, H. (1992). Elément fini mixte pour interface cohérente ou fissurée, Thèse de doctorat. Université Claude Bernard, Lyon, France.

[18] Bouziane, S., Bouzerd, H., Guenfoud, M. (2009). Mixed finite element for modelling interfaces, Eur. J. Comput. Mech., 18(2), pp. 155-75, DOI: 10.3166/ ejcm.18.155-175.

[19] Djemai, H. (2017). Contribution à l'étude de l'endommagement dans les matériaux composites sandwiches, Thèse de doctorat. Université Mohamed Khider, Biskra, Algérie. 